\title{
Effect of the Ketogenic Diet on the Activity Level of Wistar Rats
}

\author{
PATRICIA MURPHY, SERGEI S. LIKHODII, MOHAMMAD HATAMIAN, AND \\ W. MCINTYRE BURNHAM \\ Department of Pharmacology, The University of Toronto, Toronto, Ontario, Canada M9A 4X6
}

\begin{abstract}
ABST
Children, adolescents, and adults with epilepsy often also
show symptoms associated with attention-deficit/hyperactivity
disorder (ADHD). The ketogenic diet, which is administered to
children with epilepsy refractory to drug therapy, seems to
improve behavior in individuals with symptoms of ADHD. The
basis for this improvement is unknown, although it seems to be
unrelated to seizure control. The present research was designed
to investigate the effect of two ketogenic diets on the behavior of
normal adult male rats. Two experiments were conducted. In
experiment 1,36 subjects were placed on one of three diets: a
control diet, a $6.3: 1$ ketogenic diet, and a $4: 1$ ketogenic diet. In
experiment 2,20 subjects were placed either on a control diet or
on a $4: 1$ ketogenic diet. The activity level of each subject was
measured using an open field test. Time spent immobile, groom-
\end{abstract}
Attention-deficit/hyperactivity disorder (ADHD) affects children, adolescents, and adults. The symptoms of the disorder include inattentiveness, impulsiveness, and overactivity (1). The cause of the disorder is unknown, although there is evidence that it is, in part, heritable (2-4). The most common treatment for ADHD is stimulant medication.

Regardless of whether they meet DSM-IV (1) criteria for the disorder, children and adults with epilepsy often exhibit symptoms of ADHD (5-10). Both anecdotal reports $(6,11)$ and controlled studies (12) suggest that the ketogenic diet ameliorates symptoms of ADHD in individuals with epilepsy.

Attention (6,11), cognition $(12,13)$, and behavior $(6,11,12)$ have been reported to improve in individuals who have epilepsy and are on the ketogenic diet. The improvement in these domains seems to be unrelated to the level of seizure control attained (6).

The ketogenic diet is a high-fat, low-carbohydrate, and low-protein diet $(14,15)$. It is an effective treatment for intrac-

Received February 19, 2004; accepted August 2, 2004.

Correspondence: Patricia Murphy, Ph.D., University of Toronto, Department of Pharmacology, 1 King's College Circle, Room 4309, Toronto, Ontario, Canada M9A 4X6; e-mail: pattyannemurphy@hotmail.com

This experiment was supported by funds from the Michael Bahen Chair of Epilepsy Research and NSERC grant \#CHRP238016-00.

DOI: 10.1203/01.PDR.0000150804.18038.79 ing, and in exploratory behavior was measured for $600 \mathrm{~s}$. Subjects were tested once before initiation of the diets and once while on the diets. No significant group differences were found in activity level before initiation of the diets. After initiation of the diets, subjects in both ketogenic groups showed a significantly lower activity level than the rats on the control diet. The ketogenic diet decreases activity level in an animal model. This behavioral change may relate to the improved behavior seen when children with symptoms of ADHD are placed on the diet. (Pediatr Res 57: 353-357, 2005)
Abbreviation
ADHD, attention-deficit/hyperactivity disorder

table epilepsy $(5,11,12)$ and has been found to be useful in controlling seizures that have proved to be unresponsive to drug treatment in both children and adults $(15,16)$. The ketogenic diet has also been found to be effective in animal studies. It increases seizure threshold in several animal models of epilepsy (17-19). Although the mechanism by which the diet controls seizures is unknown, it is thought that the low level of carbohydrate in the diet forces the brain to take up ketone bodies instead of glucose as a fuel $(15,20,21)$.

In the present research, the effect of two different ketogenic diets on activity level was compared with that of a control diet. A ketogenic diet with a ratio of fat to carbohydrate plus protein of 6.3:1 has been used extensively in animal experiments designed to examine the anticonvulsant properties of the diet (standard diet) $(17,18)$. This diet's ratio of $6.3: 1$, however, is significantly higher than the ratio of $3: 1$ or $4: 1$ commonly used in patients who are treated with the ketogenic diet (15).

Perhaps more important, the 6.3:1 diet also is not nutritionally balanced in relation to the control diet. In particular, the 6.3:1 diet is deficient, compared with the control diet, in the amounts of protein, minerals, and vitamins that it provides. When two groups that are fed a control diet and the 6.3:1 ketogenic diet are compared, it is not possible to attribute the differences observed to a particular feature of the diet, such as 
reduced levels of carbohydrate or increased level of fats. The anticonvulsive and behavioral effects of the original 6.3:1 diet may, in fact, be due to discrepancies in protein, mineral, or vitamin content. To address this concern, a ketogenic diet with the ratio of 4:1 that matches the control diet in protein, mineral, and vitamin content (balanced diet) was developed (22) (see Table 1). The only difference between the $4: 1$ balanced ketogenic diet and the control diet is the carbohydrate and fat content.

The present research was designed to determine the effect on activity level of two ketogenic diets with different fat, protein, and carbohydrate ratios. The use of the balanced $4: 1$ ketogenic diet in the present research controls for the possible effects of imbalanced vitamin, mineral, and protein intake on behavior. Evidence that a ketogenic diet can change activity level would lend some support to the idea that ADHD can be treated by changes in diet. Two separate experiments were conducted.

\section{METHODS}

The present research was conducted in accordance with the guidelines of the Canadian Council on Animal Care and with the approval of the Animal Care Committee of the Faculty of Medicine of the University of Toronto.

Subjects. Adult male rats that weighed between 250 and $300 \mathrm{~g}$ at the start of the experiment served as subjects (Charles River Canada, St-Constant, Quebec, Canada). Subjects were housed individually in a vivarium. The environment was kept at a constant temperature $\left(21^{\circ} \mathrm{C}\right)$, and a 12-h light-dark cycle was maintained (lights on at 0700 and off at $1900 \mathrm{~h}$ ).

Open field test. The open field test was used to determine whether there were any differences in activity level between the diet groups. The open field test has been used extensively to measure this variable (22-25). Testing was conducted between the 0900 and 1200 . The open field consisted of a white box that measured $56 \times 61 \mathrm{~cm}$. The box was cleaned out between subjects. Three behaviors were measured: exploratory behavior, grooming, and immobility.

Exploratory behavior included walking and rearing. Immobility was defined as time spent immobile with 3 feet on the ground. The number of seconds spent in each behavior was timed with a stop watch. Rats were tested for $10 \mathrm{~min}(600$ s) each on two occasions: 1) 1, 2, or $3 \mathrm{~d}$ before initiation of the diets (and before fasting) and 2) after 17,18 , or $19 \mathrm{~d}$ on the diets. The test was administered as described previously by Murphy and Burnham (26). The day of testing for each rat was randomly determined.

\section{Experiment 1}

Diets and diet groups. Subjects were 36 adult male Wistar rats. Subjects were given $3 \mathrm{wk}$ to acclimate to the vivarium and then randomly divided into the following three diet groups: 1) a control diet group, 2) the standard 6.3:1 ketogenic diet group, and 3) a balanced 4:1 ketogenic diet group. Subjects were fasted for $48 \mathrm{~h}$ before being placed on the diets. All subjects then were allowed their diets and water ad libitum. The control diet was different from that usually consumed by the subjects.

Procedure for the open field test. Subjects were tested 1, 2, or $3 \mathrm{~d}$ before being placed on their respective diets and 17,18 , or $19 \mathrm{~d}$ after being placed on the diets. Day of testing was randomly determined.

Statistical analysis. Exploratory behavior and immobility were analyzed by means of a one-way ANOVA, both before and after initiation of the diets. Although grooming behavior was normally distributed before the diets were started, this was not the case at the second testing; therefore, this behavior (both tests) was analyzed by means of the Kruskal-Wallis one-way ANOVA on ranks.

\section{Experiment 2}

Diets and diet groups. Twenty adult male Wistar rats served as subjects. Two weeks after arrival from the breeding farm, subjects were randomly divided into two groups of 10 rats each. Subjects in the experimental group received the balanced $4: 1$ version of the ketogenic diet (22). The composition of each diet is indicated in Table 1. The 4:1 ketogenic diet is what is used most often clinically, and in human studies $(11,13,16)$. Rats in the control group received a control diet that was different from the usual diet of rat chow. Before being placed on their respective diets, subjects were fasted for $24 \mathrm{~h}$.

Procedure for the open field. Subjects were tested 1 or $2 \mathrm{~d}$ before being placed on their respective diets and 18 or $19 \mathrm{~d}$ after being placed on the diets. Day of testing was randomly determined.

Statistical analysis. Grooming data were not normally distributed. The immobility data and the exploratory data were normally distributed. For enabling a comparison between all the measures, the Mann-Whitney rank sum test was used to analyze data obtained from each behavioral measure.

Exploratory behavior, immobility, and grooming were analyzed separately. Group weights were analyzed by means of the $t$ test. The correlation between exploratory behavior and weight was calculated using the Pearson productmoment correlation coefficient. Results were considered significant at $p=0.05$.

\section{RESULTS}

Experiment 1. The data related to the activity levels of the subjects before the initiation of the diets are presented in Tables 2 and 3. As indicated, there were no significant differences found in

Table 1. Nutrient composition of 4:1 ketogenic diet and control diet

\begin{tabular}{|c|c|c|c|c|}
\hline \multirow[b]{2}{*}{ Macronutrient } & \multirow[b]{2}{*}{ Micronutrient } & \multirow{2}{*}{$\begin{array}{l}\text { Control } \\
(\mathrm{g} / \mathrm{kg})\end{array}$} & \multicolumn{2}{|c|}{$\mathrm{KD}$} \\
\hline & & & $\mathrm{g} / \mathrm{kg}$ & $\%$ \\
\hline Protein & Casein & 87.225 & 142.090 & \\
\hline \multirow[t]{3}{*}{ Carbohydrate } & Corn starch & 465.70 & & \\
\hline & Sucrose & 137.500 & & \\
\hline & Dextrin & 165.000 & 30.000 & 3.4 \\
\hline Fat & Lard & & 187.800 & 80.0 \\
\hline \multirow[t]{2}{*}{ Vitamins } & AIN-93G vitamin mix* & 0.330 & 0.538 & \\
\hline & Choline bitartrate & 2.500 & 4.073 & \\
\hline Minerals & AIN-93G mineral mix* & 27.300 & 44.472 & \\
\hline Fiber & Cellulose & 41.431 & 66.087 & \\
\hline Antioxidants & Tert-butylhydroquinone & 0.014 & 0.023 & \\
\hline
\end{tabular}

$\mathrm{KD}$, ketogenic diet.

* Contains no carbohydrates. 
Table 2. Exploratory behavior and immobility (seconds)

\begin{tabular}{|c|c|c|c|c|c|c|c|c|c|}
\hline & \multicolumn{2}{|c|}{ Control } & \multicolumn{2}{|c|}{ Standard KD } & \multicolumn{2}{|c|}{ Balanced KD } & \multirow[b]{2}{*}{$F$} & \multirow[b]{2}{*}{$d f$} & \multirow[b]{2}{*}{$p$} \\
\hline & Mean & $\mathrm{SD}$ & Mean & $\mathrm{SD}$ & Mean & $\mathrm{SD}$ & & & \\
\hline \multicolumn{10}{|c|}{ Before diet ( $n=12$ /group) } \\
\hline Exploratory behavior & 280.67 & 67.18 & 353.25 & 73.22 & 278.08 & 111.85 & 2.93 & 35 & 0.068 \\
\hline Immobility & 307.67 & 73.27 & 243.00 & 84.59 & 306.25 & 109.43 & 2.00 & 35 & 0.151 \\
\hline \multicolumn{10}{|l|}{ After diet ( $n=12 /$ group) } \\
\hline Exploratory behavior & $292.17^{*}$ & 93.99 & $202.75 \dagger$ & 69.27 & $139.17 \ddagger$ & 64.83 & 11.92 & 35 & 0.001 \\
\hline Immobility & $280.92 *$ & 106.43 & $381.42 \dagger$ & 69.64 & $451.33 \ddagger$ & 65.64 & 12.90 & 35 & 0.001 \\
\hline
\end{tabular}

Difference between $*$ and $\dagger$ and between $*$ and $\neq$ is statistically significant (Tukey test, 0.05).

Table 3. Grooming (seconds)

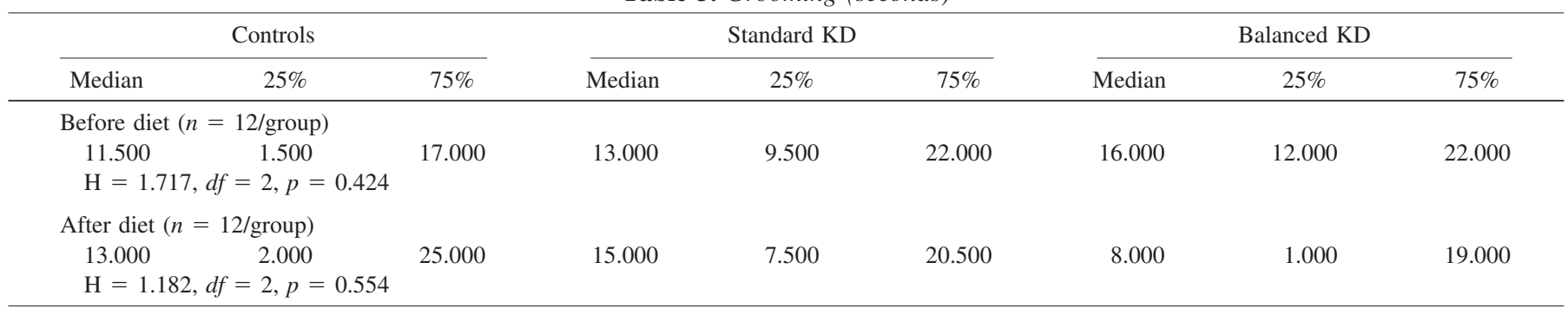

any of the measures before initiation of the diets $(p>0.05$ in all cases).

The data related to activity levels of the subjects after initiation of the diets are also presented in Tables 2 and 3. As indicated, the activity level of the rats on the two ketogenic diets was significantly lower than that of the rats on the control diet. The rats in both ketogenic diet groups spent significantly more time immobile and significantly less time in exploratory behavior than did the rats in the control group. Subsequent comparisons of the groups two at a time showed that the control group differed significantly from both ketogenic diet groups $(p<0.05)$. The ketogenic diet groups did not differ from each other $(p>0.05)$. The three groups did not differ in grooming behavior.

Experiment 2. The data related to differences in behavior before initiation of the diet are presented in Table 4. As indicated, there were no initial differences between the two groups in exploratory behavior or time spent immobile. The control subjects did spend slightly more time grooming than did the experimental animals, and this difference was significant.

The data related to differences in behavior after $18 / 19 \mathrm{~d}$ on the diets are presented in Table 4. As indicated, the experimental animals spent significantly less time than the normal controls in exploratory behavior, significantly more time immobile, and significantly less time grooming.
The data related to group weights are present in Table 5. The groups were not found to differ significantly in weight either before the start of the diet $[t=-0.605$ (18 degrees of freedom (df)), $p<0.552]$ or after the open field test $[t=1.350(\mathrm{df}=$ 18), $p=0.194]$. The correlation between weight and exploratory behavior was not found to be significant $[r=-0.0224$ $(\mathrm{df}=18), p>0.050]$.

\section{DISCUSSION}

In experiment 1, the three groups of rats did not differ on any behavioral measures before being placed on the diets. After 17, 18 , or $19 \mathrm{~d}$ on the diets, however, the two ketogenic diet groups differed from the control group in spending less time in exploratory behavior and more time immobile. No group differences were found in grooming behavior. These results indicate that the rats in the two ketogenic groups became less active after being placed on the diets. The 6.3:1 and the balanced diet were equally effective. The ketogenic groups did not differ from each other.

Although it was not possible to ensure that subjects in all groups ate an equal amount of food, subjects were checked daily, and all animals remained in good health by all outward appearances throughout the experiment. The lower activity level of the rats on the ketogenic diets therefore do not seem to be attributable to poor health.

Table 4. Exploratory, grooming, and immobility scores (in seconds)

\begin{tabular}{|c|c|c|c|c|c|c|c|c|}
\hline & \multicolumn{3}{|c|}{ Controls $(n=10)$} & \multicolumn{3}{|c|}{ Ketogenic $(n=10)$} & \multirow[b]{2}{*}{$T$} & \multirow[b]{2}{*}{$p$} \\
\hline & Median & $25 \%$ & $75 \%$ & Median & $25 \%$ & $75 \%$ & & \\
\hline \multicolumn{9}{|l|}{ Before diet } \\
\hline Immobility & 327.50 & 235.00 & 504.00 & 316.00 & 284.00 & 383.00 & 106.00 & $<0.970$ \\
\hline Grooming & 21.00 & 5.00 & 27.00 & 0.00 & 0.00 & 6.00 & 131.50 & $<0.049$ \\
\hline \multicolumn{9}{|l|}{ After diet } \\
\hline Grooming & 30.00 & 19.00 & 33.00 & 6.500 & 0.00 & 18.00 & 138.00 & 0.014 \\
\hline
\end{tabular}


Table 5. Group weights (grams)

\begin{tabular}{lcccc}
\hline Group & $N$ & Mean & SD & SEM \\
\hline Before diet & & & & 8.835 \\
KD & 10 & 287.500 & 9.615 & 2.794 \\
Control diet & 10 & 290.000 & & 3.040 \\
Open field & & & 17.378 & 5.496 \\
KD & 10 & 401.300 & 24.713 & 7.815 \\
Control diet & 10 & 388.400 & & \\
\hline
\end{tabular}

Subjects were not weighed in this experiment, but any association between weight and activity level would have been strictly correlational, and no causal relationship could have been inferred from the data. No animal showed any signs of sedation or ataxia as described by Loscher et al. (27).

In experiment 2, the animals on the ketogenic diet spent significantly less time in exploratory behavior than did the subjects on the control diet. Inversely, the subjects on the ketogenic diet spent significantly more time immobile than did the control subjects. There were no group differences in these behaviors before the subjects were started on their respective diets. The control rats spent more time grooming, but as this was the case both before and after initiation of the diets, this difference cannot be attributed to the ketogenic diet.

All subjects were kept in the animal colony and cared for by the staff of the Department of Medicine at the University of Toronto. All subjects were handled regularly by the researcher. None of the animals in either group showed any outward signs of ill health or odd behavior. As in the previous experiment none of the animals showed any signs of sedation or ataxia as described by Loscher et al. (27).

The animals in experiment 2 were weighed both before being placed on the diets and after the second open field test while on the diets. No group difference in weight was found at either time point. Although a difference in weight could not have been used to explain the behavioral change, these results show that it was not a factor at all.

As stated, the animals in the present experiments did not show any outward signs of ill health. In an experiment on the behavioral effects of the ketogenic diet, Zhao et al. (28) did find the diet to have detrimental effects on body growth, brain growth, and cognitive functioning. Zhao et al. (28), however, used a diet with a ratio of fat to carbohydrate and protein of 8.6:1. The present research used ketogenic diets with ratios of 6.3:1 and 4:1. The results of Zhao et al. (28), therefore, cannot be compared with those of the present research. Zhao et al. also placed their subjects on the diets at approximately the age of weaning. In the present experiment, subjects were started on the diets as adults. The detrimental effects found by Zhao et al. (28) could have been due to the stress of being placed on a very high-fat diet at weaning. In any event, a number of experiments examining the effects of various ketogenic diets have reported no obvious ill effects on health $(17,18)$. In addition, Bough et al. (18) found that a 6.3:1 diet does not seem to be neurotoxic.

An experiment conducted by Hori et al. (29) examined the effect of the 6.3:1 ketogenic diet on activity level using a mixed open field and novel/familiar objects test. The subjects were allowed to roam freely in the open field for a period of $60 \mathrm{~s}$, during five trials on 4 consecutive days. The box was divided into 64 squares (each $7.6 \times 7.6$ ), and the subjects were scored on number of rears, number of blocks crossed, and time spent investigating the objects. No difference in activity level between the diet groups was found.

Zhao et al. (28) also found no difference in activity level between rats on a ketogenic diet and rats on a control diet. Putting aside the issue of the 8.6:1 ketogenic diet used, Zhao et al. (28) tested for only $2 \mathrm{~min}$ on 2 consecutive days. In addition, only the number of squares crossed was used as a measurement of activity level.

In the present research, the open field test was scored differently. Probably the crucial difference from Hori et al. (29) and Zhao et al. (28) is that exploratory behavior (locomotion and rearing) was measured in time spent in the behavior rather than in number of squares crossed. This is important as the experimental rats did spend a large amount of time rearing and looking around. This is an active behavior, but no squares were being crossed. In addition, the present experiments tested the subjects in the open field for a longer period of time, perhaps giving the subjects time to adapt to the environment and permitting a better sample of pure activity level. Finally, in the present research, no novel objects were placed in the open field. The use of novel in the experiment of Hori et al. (29) may have disrupted the subjects' locomotory activity and interfered with measurement.

The anticonvulsant effects and the behavioral effects of the ketogenic diet may come about through different mechanisms. As previously discussed, seizure control and behavioral change seem to be separable $(6,12)$. It has been suggested that ketosis is necessary to achieve seizure control, but this has not been proven. It may or may not be necessary to achieve ketosis to bring about behavioral change. The behavioral changes reported in the literature may simply be due to the low carbohydrate levels or high fat levels contained in the ketogenic diet. As the protein, mineral, and vitamin content of the modified 4:1 ketogenic diet used in the present experiments matched that of the control diet, any differences in behavior can be attributed to the reduced carbohydrate content or increased fat content of the ketogenic diet.

There has been considerable speculation that sugar (sucrose) may cause ADHD. Research has shown that parents and teachers believe that the ingestion of sugar can cause the symptoms associated with ADHD (30), although research has not supported this idea (31-34). The ketogenic diet, however, does not simply remove sugar from the diet; the level of all carbohydrates is drastically reduced from that contained in a normal diet.

Often, the studies investigating the link between ADHD and sugar have been designed to pit the effects of sugar against the effects of artificial sweeteners (32-34). The present research 
differs in that the level of carbohydrates was greatly reduced from the amount ingested as part of a normal diet. The present experiment does not suggest that sugar causes ADHD but rather that a decrease in carbohydrates may lessen the symptoms of ADHD. It may also be, of course, that the behavioral differences found could have been caused by the increased amount of fat contained in the ketogenic diet.

The results of the present experiment are in keeping with clinical research that has found an improvement in behavior in children and adults who are placed on the ketogenic diet for reasons of seizure control (6,11-13). The present research suggests that the ketogenic diet decreases activity level. Clinical research examining the behavioral effects of the ketogenic diet has shown an improvement in attention $(6,11)$. The results from clinical studies and the present experiments suggest that individuals with ADHD might benefit from being placed on the ketogenic diet. It should be noted, however, that although a higher level of activity than normal is a symptom of ADHD and activity level has been studied in individuals with ADHD (35), activity level is not a specific model for the disorder.

The present experiment examined the effect of the ketogenic diet on adult animals, and it perhaps could be argued that the results cannot be generalized to children or adolescents. Clinical research has shown, however, significant improvements in behavior in children, adolescents, and adults on the diet. It does seem, then, that in humans, the diet can affect all age groups. It might also be argued that the body uses ketones differently at different ages and therefore the results cannot be generalized to different age groups. There is no evidence, however, that ketosis is necessary for a behavioral change.

There are considerations to placing individuals with behavioral problems on the diet. The diets with ratios of $4: 1$ or $3: 1$ are used only as a last resort in children with seizures that are refractory to drug therapy. Because of the high fat and low carbohydrate content, the diet is considered unpalatable and difficult to follow. In addition, there are potentially serious health problems associated with the diet (36). Children with intractable epilepsy are kept on the diet for 2-3 y only (5). It may be possible, however, to design a less restrictive diet to treat ADHD, perhaps with a $2: 1,1: 1$, or even lower ratio of fat to carbohydrate plus protein.

Finally, it should be mentioned that Zhao et al. (28) found that rats that were placed on a 8.3:1 ketogenic diet exhibited decreased body growth, impaired brain growth, and impaired visual-spatial learning and memory. It should be noted, however, that this ratio of fat to carbohydrate and protein is unusually high and is not used clinically. Clinical research has found improvements in cognition in adults and children on the ketogenic diet $(12,13)$. Further research is needed on the cognitive effects of the $4: 1$ diet.

\section{REFERENCES}

1. American Psychiatric Association 1994 Diagnostic and Statistical Manual of Mental Disorder, 4th Ed. American Psychiatric Association, Washington, DC
2. Biederman J, Faraone SV, Keenan K, Knee D, Tsuang MT 1990 Family-genetic and psychosocial risk factors in DSM-III attention deficit disorder. J Am Acad Child Adolesc Psychiatry 29:526-533

3. Cantwell DP 1975 Genetics of hyperactivity. J Child Psychol Psychiatry 16:261-264

4. Dalby JT, Fox SL, Haslam RH 1982 Adoption and foster care rates in paediatric disorders. J Dev Behav Pediatr 3:61-64

5. Katyal NG, Koehler AN, McGhee B, Foley CM, Crumrine PK 2000 The ketogenic diet in refractory epilepsy: the experience of Children's Hospital of Pittsburgh. Clin Pediatr (Phila) 39:153-159

6. MacCracken KA, Scalisi JC 1999 Development and evaluation of a ketogenic diet program. J Am Diet Assoc 99:1554-1558

7. Ounsted C 1955 The hyperkinetic syndrome in epileptic children. Lancet 269:303311

8. Semrud-Clikeman M, Wical B 1999 Components of attention in children with complex partial seizures with and without ADHD. Epilepsia 40:211-215

9. Smith DB, Craft BR, Collins J, Mattson RH, Cramer JA 1986 Behavioral characteristics of epilepsy patients compared with normal controls. Epilepsia 27:760-768

10. Stores G 1978 School-children with epilepsy at risk for learning and behaviour problems. Dev Med Child Neurol 20:502-508

11. Kinsman SL, Vining EP, Quaskey SA, Mellits D, Freeman JM 1992 Efficacy of the ketogenic diet for intractable seizure disorder: review of 58 cases. Epilepsia 33:1132-1136

12. Pulsifer MB, Gordon JM, Brandt J, Vining EP, Freeman JM 2001 Effects of ketogenic diet on development and behavior: preliminary report of a prospective study. Dev Med Child Neurol 43:301-306

13. Sirven J, Whedon B, Caplan D, Liporace J, Glosser D, O’Dwyer J, Sperling MR 1999 The ketogenic diet for intractable epilepsy in adults: preliminary results. Epilepsia 40:1721-1726

14. Peterman MG 1924 The ketogenic diet in the treatment of epilepsy: a preliminary report. Am J Dis Child 28:28-33

15. Swink TD, Vining EP, Freeman JM 1997 The ketogenic diet. Adv Pediatr 44:297-329

16. Freeman JM, Vining EP, Pillas DJ, Pyzik PL, Casey JC, Kelly LM 1998 The efficacy of the ketogenic diet-1998: a prospective evaluation of intervention in 150 children. Pediatrics 102:1358-1363

17. Bough KJ, Eagles DA 1999 A ketogenic diet increases the resistance to pentylenetetrazole-induced seizures in the rat. Epilepsia 40:138-143

18. Bough KJ, Yao SG, Eagles DA 2000 Higher ketogenic diet ratios confer protection from seizures without neurotoxicity. Epilepsy Res 38:15-25

19. Likhodii SS, Musa K, Mendonca A, Dell C, Burnham WM, Cunnane SC 2000 Dietary fat, ketosis and seizure resistance in rats on the ketogenic diet. Epilepsia 41:1400-1410

20. Prasad AN, Stafstrom CF, Holmes GL 1996 Alternative epilepsy therapies: the ketogenic diet, immunoglobulins, and steroids. Epilepsia 37:S81-S95

21. Stafstrom CE 1999 Animal models of the ketogenic diet: what have we learned, what can we learn? Epilepsy Res 37:241-259

22. Likhodii S 2001 Experiments in the rat pentylenetetrazole infusion threshold model of the ketogenic diet. Epilepsy Res 44:83-86

23. Ehlers CL, Koob GF 1985 Locomotor behavior following kindling in three different brain sites. Brain Res 326:71-79

24. Mohapel P, McIntyre DC 1998 Amygdala kindling-resistant (SLOW) or Prone (FAST) rat strains show differential fear responses. Behav Neurosci 112:14021413

25. Varty GB, Paulus MP, Braff DL, Geyer MA 2000 Environmental enrichment and isolation rearing in the rat: effect on locomotor behavior and startle response plasticity. Biol Psychiatry 47:864-873

26. Murphy P, Burnham WM 2003 The effect of kindled seizures on the locomotory behavior of Long-Evans rats. Exp Neurol 180:88-92

27. Loscher W, Honack D, Hashem A 1987 Anticonvulsant efficacy of clonazepam and the $\beta$-carboline ZK 93423 during chronic treatment in amygdala-kindled rats. Eur J Pharmacol 43:403-414

28. Zhao Q, Stafstrom CE, Fu DD, Hu Y, Holmes GL 2004 Detrimental effects of the ketogenic diet on cognitive function in rats. Pediatr Res 55:498-506

29. Hori A, Tandon P, Holmes GL, Stafstrom CE 1997 Ketogenic diet: effects on expression of kindled seizures and behaviour in adult rats. Epilepsia 38:750-758

30. DiBattista D, Shepherd ML 1993 Primary school teachers beliefs and advice to parents concerning sugar consumption and activity in children. Psychol Rep $72: 47-55$

31. Milich R, Pelham WE 1986 Effects of sugar ingestion on the classroom and playgroup behavior of attention deficit disordered boys. J Consult Clin Psychol 54:714-718

32. Rapoport JL 1986 Diet and hyperactivity. Nutr Rev 44:158-162

33. Roshon MS, Hagen RL 1989 Sugar consumption, locomotion, task orientation and learning in preschool children. J Abnorm Child Psychol 17:349-357

34. Wolraich ML, Lindgren SD, Stumbo PJ, Stegink LD, Appelbaum MI, Kiritsy MC 1994 Effects of diets high in sucrose or aspartame on the behavior and cognitive performance of children. N Engl J Med 330:301-307

35. Pinto LP, Tryon WW 1996 Activity measurements support dimensional assessment Behav Modif 20:243-258

36. Ballaban-Gil K, Callahan C, O’Dell C, Pappo M, Moshe S, Shinnar S 1998 Complications of the ketogenic diet. Epilepsia 39:744-748 